\title{
A prospective study of prevalence of anti-microbial susceptibility of bacterial isolates in lower respiratory tract infections
}

\author{
Ajaz Hussain*, Qursheed Sultana, M. Abdur Rab Ansari
}

Department of Microbiology, Deccan College of Medical Sciences, Hyderabad, Telangana, India

\author{
Received: 05 April 2021 \\ Accepted: 08 July 2021 \\ *Correspondence: \\ Dr. Ajaz Hussain, \\ Email: mdajazhussain@gmail.com
}

Copyright: (c) the author(s), publisher and licensee Medip Academy. This is an open-access article distributed under the terms of the Creative Commons Attribution Non-Commercial License, which permits unrestricted non-commercial use, distribution, and reproduction in any medium, provided the original work is properly cited.

\begin{abstract}
Background: Lower respiratory tract infections (LRTIs) is one of the most common causes of mortality and morbidity across all age groups. In recent years, antibiotic resistance is constantly increasing. Thus, there is a need to monitor the bacteriological profile of pathogenic organisms. The present study aims to identify bacterial pathogens and their antibiotic susceptibility pattern.

Methods: A prospective, observational, single centered study was conducted at tertiary care hospital for a period of 1 year i.e. from March 2016 to March 2017. A total of 733 sputum samples were collected and analyzed in microbiology lab. The samples went subjected to microscopy testing, culture and antibiotic sensitivity using suitable bacteriological methods.

Results: From 733 sputum samples, about $51.34 \%$ were males and $48.56 \%$ were females. Approximately $49.65 \%$ of total samples were growth positive. Klebsiella was found to be the predominant microorganism followed by Methicillin sensitive Staphylococcus aureus (MSSA) and streptococcus. The gram-negative bacteria showed highest sensitivity for piperacillin/tazobactam, imipenem and ciprofloxacin. The gram-positive bacteria were found to be more susceptible for vancomycin, teicoplanin and amikacin.

Conclusions: LRTIs are contagious form of disease and can rapidly disseminate among community. The irrational use of antibiotics complicates the management due to the antibiotic resistance. Local trend of antibiotic susceptibility pattern should be known as it helps in increasing the appropriate use of the antibiotics, decreasing the mortality and morbidity and reduces the anti-microbial resistance.
\end{abstract}

Keywords: Antibiotic susceptibility, Antimicrobial resistance, Sputum, LRTI, Drug sensitivity

\section{INTRODUCTION}

Respiratory tract infections are one of the most prevalent type of infections across the globe. Among respiratory tract infections, lower respiratory tract infections (LRTIs) has the most profound impact on both mortality and morbidity across all age groups. ${ }^{1}$ The clinical presentations for the LRTIs varies depending upon the severity of the disease. With young healthy adults affected with LRTI showing non-pneumonic symptoms to pneumonia like symptoms or exacerbation of existing illnesses such as chronic obstructive pulmonary diseases (COPD). ${ }^{2}$
Several factors play cardinal role in the prevalence of the LRTIs. These include age, gender, occupation, environmental factors and season. Respiratory infections not only increases the frequency of prescriptions of antibiotics but also impacts the work of the patients negatively and raises the burden on the society economically. Management of LRTIs are considered as a challenge as they increases the burden on the society economically more than that of ischemic heart diseases, cancer, malaria or HIV. ${ }^{3,4}$

Most of the LRTIs are caused by viruses, however, there could be other causative pathogenic organisms as well 
such as atypical organisms- bacteria, or fungi. ${ }^{5}$ Identification of the causative agents helps to map out the strategy for the management of the infection. In developing countries like India, development of such strategy will help in rapid diagnosis, accurate use of empirical therapy and switch to the most sensitive antibiotic based on the antibiogram of the organism isolate in order to curb the spread of the infection in the community and thus, preventing the complications. ${ }^{3,6}$

In recent times, there is a drastic increase in the incidences of the respiratory bacterial resistance towards various antibiotics, further complicating the management of the disease. Antibiotic resistance can be caused by various factors such as overuse or irrational administration of antibiotics, transmission of the resistant strains from patients to healthcare professionals or vice versa. ${ }^{7}$ This underlines a growing concern around the globe especially among the medicinal and research community regarding the efforts to prevent the antibiotic resistance. However, there is lack of data on the pathogens involved in LRTIs and their antibiotic susceptibility patterns.

The present study was designed to identify the isolated bacterial pathogens and to evaluate their sensitivity pattern for various antibiotics among patients with LRTIs by testing the collected sputum samples.

\section{METHODS}

\section{Study design}

The present study was an observational, prospective and single centered, conducted for a period of 1 year from March 2016 to March 2017 in Princess Esra Hospital, a tertiary care hospital in Hyderabad. The study was started after obtaining the ethical committee approval. Sputum samples were received in the microbiology department and were analyzed for the presence of bacteria and their antibiotic susceptibility profile.

\section{Sample collection}

A total of 733 sputum samples were collected from various hospital wards. All the patients had clinical presentation for the LRTI. The study didn't include the repeated sample from the patients. The samples were collected in wide mouthed sterile containers with labels that were immediately brought to the microbiology department.

\section{Specimen culture}

Prior to the culture, samples were investigated by microscopy to detect the presence of pathogens- number and types of organisms. The samples were then subjected to the culture media in order to identify the bacterial pathogens. The sputum samples were cultured on blood agar, chocolate agar and McConkey agar. The chocolate agar plates were incubated for $24-48$ hours at $37{ }^{0} \mathrm{C}$ whereas blood agar plates and McConkey agar plates were incubated for 24 hours at $37{ }^{\circ} \mathrm{C}$.

Suspected colonies were then cultured in suitable solid media and then preserved on agar slants. These agar slants were refrigerated at $4{ }^{\circ} \mathrm{C}$ for further analysis.

\section{Isolation of the pathogen}

The isolated pathogens were identified using morphological colony studies, gram staining reactions and suitable biochemical tests. $>140 \mathrm{CFU} / \mathrm{ml}$ of colony count was considered as significant.

\section{Antibiotic susceptibility test}

The antibiotic susceptibility test was performed using Kirby Bauer's disc diffusion method as per the clinical and laboratory standards institute (CLSI) guidelines.

For gram positive organisms to penicillin 10 units, azithromycin $15 \mathrm{mcg}$, cotrimoxazole $25 \mathrm{mcg}$, ciprofloxacin $5 \mathrm{mcg}$, clarithromycin $15 \mathrm{mcg}$, levofloxacin $5 \mathrm{mcg}$, doxycycline $30 \mathrm{mcg}$, amoxicillin/clavulanic acid 20/10 mcg, amikacin $30 \mathrm{mcg}$, teicoplanin $30 \mathrm{mcg}$, vancomycin $30 \mathrm{mcg}$ and linezolid $30 \mathrm{mcg}$.

For gram negative organisms to ampicillin $30 \mathrm{mcg}$, cotrimoxazole $25 \mathrm{mcg}$, ciprofloxacin $5 \mathrm{mcg}$, amikacin 30 mcg, ceftriaxone $30 \mathrm{mcg}$, ceftazidime $30 \mathrm{mcg}$, ceftazidime/clavulanic acid 30/10 mcg, cefepime $30 \mathrm{mcg}$, levofloxacin $5 \mathrm{mcg}$, piperacillin/tazobactam 100/10 mcg, imipenem $10 \mathrm{mcg}$, cefuroxime $30 \mathrm{mcg}$, gentamicin $10 \mathrm{mcg}$ and tigecycline $15 \mathrm{mcg}$. Cephoxitin is used as an indicator for the methicillin resistant Staphylococcus aureus. The data collected was analyzed using Microsoft excel.

\section{RESULTS}

Out of 733 sputum samples analyzed, 364 (49.65\%) were found to be culture positive. Among the culture positive samples, $237(32.33 \%)$ isolates were gram negative and $127(17.34 \%)$ were gram positive pathogens.

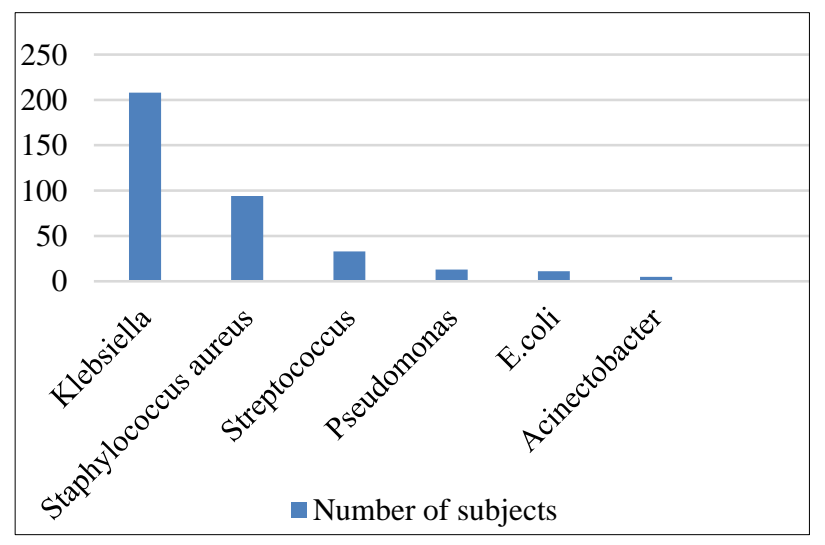

Figure 1: Bacterial pathogens identified. 
Table 1: Baseline characteristics.

\begin{tabular}{|lll|}
\hline Age distribution & $\begin{array}{l}\text { Number } \\
\text { of subjects }\end{array}$ & $\begin{array}{l}\text { Percentage } \\
\text { of subjects }\end{array}$ \\
\hline $0-10$ & 20 & 2.72 \\
\hline $11-20$ & 61 & 8.32 \\
\hline $21-30$ & 76 & 10.36 \\
\hline $31-40$ & 88 & 12 \\
\hline $41-50$ & 117 & 15.96 \\
\hline $51-60$ & 156 & 21.28 \\
\hline $61-70$ & 121 & 16.5 \\
\hline $71-80$ & 68 & 9.27 \\
\hline $81-90$ & 21 & 2.86 \\
\hline $91-100$ & 5 & 0.68 \\
\hline Gender & & \\
\hline Male & 377 & 51.34 \\
\hline Female & 356 & 48.56 \\
\hline Total & 733 & 100 \\
\hline
\end{tabular}

The most commonly isolated pathogens were Klebsiella (208), Staphylococcus aureus (94) and Streptococcus (33).

The gram negative pathogens showed highest antibiotic sensitivity for piperacillin/tazobactam, imipenem and ciprofloxacin. On the other hand, gram positive isolates showed most antibiotic sensitivity for vancomycin, teicloplanin and linezolid. Mixed bacterial growth was considered as culture negative

Table 2: Distribution of samples according to bacterial growth.

\begin{tabular}{|lll|}
\hline Sample distribution & $\begin{array}{l}\text { Number } \\
\text { of subjects }\end{array}$ & $\begin{array}{l}\text { Percentage } \\
\text { of subjects }\end{array}$ \\
\hline Culture negative & 369 & 50.34 \\
\hline Culture positive & 364 & 49.65 \\
\hline Gram positive bacteria & 127 & 17.32 \\
\hline Gram negative bacteria & 237 & 32.33 \\
\hline
\end{tabular}

Table 3: Antibiotic susceptibility of gram-negative isolates.

\begin{tabular}{|llllll|}
\hline $\begin{array}{l}\text { SI. } \\
\text { no. }\end{array}$ & Antibiotics & $\begin{array}{l}\text { Klebisella } \\
(\mathbf{n = 2 0 8})\end{array}$ & Pseudomonas $(\mathbf{n = 1 3})$ & $\begin{array}{l}\text { E. coli } \\
(\mathbf{n = 1 1})\end{array}$ & $\begin{array}{l}\text { Acinectobacter } \\
(\mathbf{n = 5})\end{array}$ \\
\hline $\mathbf{1}$ & Ampicillin & $30(14.4)$ & $1(7.69)$ & $2(18.18)$ & $\mathrm{NT}^{*}$ \\
\hline $\mathbf{2}$ & Cotrimoxazole & $107(51.44)$ & $5(38.46)$ & $4(36.36)$ & $2(40)$ \\
\hline $\mathbf{3}$ & Ciprofloxacin & $184(88.46)$ & $9(69.23)$ & $7(63.63)$ & $3(60)$ \\
\hline $\mathbf{4}$ & Amikacin & $171(82.21)$ & $10(76.92)$ & 0 & $1(20)$ \\
\hline $\mathbf{5}$ & Ceftriaxone & $145(69.71)$ & $7(53.84)$ & $7(63.63)$ & $4(80)$ \\
\hline $\mathbf{6}$ & Ceftazidime & $132(63.46)$ & $8(61.53)$ & $7(63.63)$ & $3(60)$ \\
\hline $\mathbf{7}$ & Ceftazidime/clavulaunic acid & $163(78.36)$ & $10(76.92)$ & $8(72.72)$ & $4(80)$ \\
\hline $\mathbf{8}$ & Cefepime & $145(69.71)$ & $9(69.23)$ & $8(72.72)$ & $3(60)$ \\
\hline $\mathbf{9}$ & Levofloxacin & $166(79.80)$ & $10(76.92)$ & $8(72.72)$ & $3(60)$ \\
\hline $\mathbf{1 0}$ & Piperacillin/tazobactum & $185(88.94)$ & $12(92.30)$ & $11(100)$ & $5(100)$ \\
\hline $\mathbf{1 1}$ & Imipenem & $185(88.94)$ & $10(76.92)$ & $9(81.81)$ & $4(80)$ \\
\hline $\mathbf{1 2}$ & Cefuroxime & $72(34.67)$ & $4(30.76)$ & $4(36.36)$ & $1(20)$ \\
\hline $\mathbf{1 3}$ & Gentamicin & $92(44.23)$ & $7(53.84)$ & $6(54.54)$ & $1(20)$ \\
\hline $\mathbf{1 4}$ & Tigecycline & $147(70.67)$ & NT & $8(72.72)$ & $3(60)$ \\
\hline
\end{tabular}

*NT- Not tested

Table 4: Antibiotic susceptibility of gram-positive isolates.

\begin{tabular}{|lllll|}
\hline SI. no & Antibiotics & MSSA $(\mathbf{n = 8 1})$ & MRSA $(\mathbf{n = 1 3})$ & Streptococcus $(\mathbf{n = 3 3})$ \\
\hline $\mathbf{1}$ & Penicillin & $30(37.03)$ & 0 & $33(100)$ \\
\hline $\mathbf{2}$ & Azithromycin & $57(70.37)$ & 0 & $25(75.75)$ \\
\hline $\mathbf{3}$ & Cotrimoxazole & $51(62.96)$ & 0 & $26(78.78)$ \\
\hline $\mathbf{4}$ & Ciprofloxacin & $53(65.43)$ & 0 & $29(87.87)$ \\
\hline $\mathbf{5}$ & Clarithromycin & $61(75.30)$ & $4(30.76)$ & $30(90.90)$ \\
\hline $\mathbf{6}$ & Levofloxacin & $63(77.77)$ & $10(76.92)$ & $26(78.78)$ \\
\hline $\mathbf{7}$ & Tetracycline & $77(95.06)$ & $2(15.38)$ & $25(75.75)$ \\
\hline $\mathbf{8}$ & Doxycycline & $76(93.82)$ & $4(30.76)$ & $31(93.93)$ \\
\hline $\mathbf{9}$ & Amoxicillin/clavulanic acid & $68(83.09)$ & $3(23.07)$ & $29(87.87)$ \\
\hline $\mathbf{1 0}$ & Amikacin & $77(95.06)$ & $10(76.92)$ & $31(93.93)$ \\
\hline $\mathbf{1 1}$ & Teicoplanin & $78(96.29)$ & $12(92.30)$ & $29(87.87)$ \\
\hline $\mathbf{1 2}$ & Vancomycin & $78(96.29)$ & $12(92.30)$ & $31(93.93)$ \\
\hline $\mathbf{1 3}$ & Linezolid & $76(93.82)$ & $12(92.30)$ & $32(96.96)$ \\
\hline
\end{tabular}




\section{DISCUSSION}

The aim of the present study was to study the prevalence of the bacteria causing LRTs in tertiary care hospital in India. Our study helps to understand the pathogenic organisms associated with LRTIs and their anti-microbial sensitivity profiles. We collected and analyzed a total of 733 samples, out of which $364(49.65 \%)$ were culture positive and the rest $369(50.34 \%)$ were culture negative with no pathogenic organism. Previous studies conducted in Southeast Asia have reported rate of about $45-80 \%$ in case of identifying the bacterial etiological isolates in LRTIs. $^{8,9}$

The prevalence of LRTIs were more commonly found in males than in females (Table 1). Multiple factors are responsible for increasing the risk of the infection among males such as alcohol consumption, use of tobacco and smoking cigarettes. ${ }^{8}$ These factors lowers an individual's local immunity in respiratory tract as impairment of mucociliary clearance increases, mucous plugs in the airways and alveoli becomes dysfunctional due to collapse. ${ }^{10}$ Additionally, females included in our study were mostly housewives who were not exposed extensively to these risk factors.

In the present study, highest number of patients were of age group 51-60 (21.28\%) followed by 61-70 years $(16.5 \%)$ (Table 1). Our results corroborate with another study conducted by Barlett et al that reported the greatest number of incidences of LRTI among patients more than 50 years of age. This can be due to the decreased immunity present in elderly patients. ${ }^{10}$

Elderly patients are more prone to gram negative bacteria as they have weaker immunity and impaired respiratory defense functioning, along with the presence of underlying diseases such as diabetes mellitus, malnutrition and emphysema etc. Use of multiple antibiotics further complicates the condition, as it can lead to the development of multi drug resistance strains. ${ }^{11}$

Among the culture positive isolates, gram negative bacteria were $32.33 \%$ and gram positive $17.32 \%$ (Table 2). Several Indian studies have revealed the predominance of gram-negative stains in LRTIs. Among gram negative bacteria Klebsiella (208-87.7.1\%) was found to be the most common organism to be isolated followed by Pseudomonas (13-5.48\%). Shailaja et al, Ratna et al and Verma et al have also reported similar results with Klebsiella $(32.26 \%)$ to be the most predominantly isolated pathogen. ${ }^{12-14}$ However, in certain studies Pseudomonas was the most commonly isolated pathogen. Such variations in the isolated pathogens could be due to differences in age groups, seasons and individuals who are at higher risk. ${ }^{13}$

Staphylococcus aureus has been reported as the most common pathogen causing nosocomial respiratory infections. ${ }^{15}$ In our study among gram positive bacteria,
MSSA (81-63,17\%) was found to be the predominant isolate followed by MRSA (13-10.23\%) and Streptococcus (33-25.98\%) (Table 5).

The gram-negative bacteria were most sensitive to piperacillin/tazobactam and imipenem, followed by ciprofloxacin (Table 4). Drugs that were found to show highest resistance were cotrimoxazole, ofloxacin and ceftazidime. Numerous studies have also reported variations in resistance rate of the isolated organisms. ${ }^{3,16}$ Ahmed et al have also reported that piperacillin/tazobactam showed highest sensitivity among gram negative isolates. However, Nidhi et al, and Sarmah et al found amoxyclav to be more sensitive against gram negative bacteria. ${ }^{16,17}$

Our study reported that the gram-positive bacteria showed $100 \%$ sensitivity for vancomycin and teicoplanin. Penicillin, cotrimoxazole and ciprofloxacin showed highest resistance. $10.23 \%$ Staphylococcus aureus isolates were MRSA. These results are in concordance to Mishra et al and Okesola et al who have reported higher sensitivity of gram positive pathogens towards vancomycin and teicloplenin. ${ }^{18,19}$ In contrast, Gauchan et al showed that cotrimoxazole was the most effective antimicrobial against gram positive bacteria. ${ }^{3}$

\section{Limitations}

In the present study, limited number of antibiotics were used to analyze microbial antibiotic sensitivity pattern. Including large number of samples with wide range of antibiotics being used for testing in regular intervals will help in detecting more precise sensitivity patterns among bacterial pathogens.

\section{CONCLUSION}

LRTIs comprises of range of lung diseases from acute bronchitis to severe life-threatening pneumonia. The present study has reported that several pathogens are involved in its development. The growing antibiotic resistance poses a challenge for the management of LRTI, especially in elderly patients. Additionally, the rise of antimicrobial resistance towards the commonly prescribed antibiotics needs to be addressed, as it has become a global health problem. The resistance can develop due to numerous reasons such as irrational drug use, overuse or abuse of antibiotics and microorganisms undergoing genetic mutations to develop resistance towards specific class of antibiotics. Early accurate identification of the causative microorganism and their antibiotic susceptibility pattern helps in tailoring the antibiotic therapy. Our study has revealed the current bacteriological pattern for various antibiotics prescribed for the treatment of the LRTIs. The emerging antibiotic resistance needs to be kept under check. Clinicians should initiate the empirical therapy and change the choice of drug based on the sensitivity pattern for causative agent after the testing is completed. 
Funding: No funding sources

Conflict of interest: None declared

Ethical approval: The study was approved by the Institutional Ethics Committee

\section{REFERENCES}

1. Deshpande A. Epidemiology of community acquired pneumonia. JAPI. 2012;60:S6.

2. Regional situation on health statistics reporting. Health Situation in the SouthEast Asia Region 19941997. New Delhi: EHI/WHO-SEARO. 2007.

3. Gauchan P, Lekhak B, Sherchand JB. The Prevalence of lower respiratory tract infection in adults visiting Tribhuvan University Teaching Hospital. J Inst Med. 2006;28(2):10-4.

4. Gagneja D, Goel N, Aggarwal R, Chaudhary U. Changing trend of antimicrobial resistance among gramnegative bacilli isolated from lower respiratory tract of ICU patients: A 5-year study. Indian J Crit Care Med. 2011;15:164-7.

5. Tripathi PC, Dhote K. Lower respiratory tract infections: Current etiological trends and antibiogram. J Pharm Biomed Sci. 2014;4:249-55.

6. Imani R, Rouchi H, Ganji F. Prevalence of antibiotic resistance among bacteria isolates of lower respiratory tract infection in COPD Shahrekord - Iran, 2005. Pak J Med Sc. 2007;23:438-40.

7. Mahmoud A, Balkhy HH. The prevalence of antimicrobial resistance in clinical isolates from Gulf Corporation Council countries. Antimicrob Resist Infect Contl. 2012;1:26-31.

8. Panda S, Prema Nandini B, Ramani TV. Lower respiratory tract infection- bacteriological profile and antibiogram pattern. Int J Cur Res Rev. 2012;4:14955.

9. Bansal S, Kashyap S, Pal LS, Goel A. Clinical and bacteriological profile of community acquired pneumonia in Shimla, Himachal Pradesh. Indian J Chest Dis Allied Sci. 2004;46(1):17-22.

10. Barlett JG, Dowell SF, Mandell LA, File TM, Musher DM, Fine MJ. Practice guidelines for the management of community acquired pneumonia in adults. Infectious Diseases Society of America. Clin Infect Dis. 2000;31(2):347-82.
11. De Roux A, Ewig S, Garcia E, Marcos MA, Mensa J, Lode $\mathrm{H}$, et al. Mixed community acquired pneumonia in Hospitalised patients. Eur Respir J. 2006;27(4):795800.

12. Shailaja VV, Pai LA, Mathur DR, Lakshmi V. Prevalence of Bacterial and Fungal Agents Causing Lower Respiratory Tract Infections in Patients with Human Immunodeficiency Virus Infection. Indian J Med Microbiol. 2004;22(1):28-33.

13. Ratna S. Bacteriological Profile and Antibiotic Susceptibility Pattern of Lower Respiratory Tract Infection in A Tertiary Hospital In North-East India. Int J Recent Sci Res. 2017;8(9):20337-40.

14. Verma D, Kumar P, Saxena N. Bacteriological Profile and Antibiogram Pattern in Lower Respiratory Tract Infection in Kota Region (Raj). Research \& Reviews: J Microbiol Virol. 2016;6(2):13-7.

15. National Nosocomial Infections Surveillance (NNIS) system report, data summary from January 1992-April 2000, issued June 2000. Am J Infect Control. 2000;28(6):429-48.

16. Goel N, Chaudhary U, Aggrawal R, Bala K. Antibiotic sensitivity pattern of gram negative bacilli isolated from lower respiratory tract of ventilated patients of intensive care unit. Indian $\mathbf{J}$ Crit Care Med. 2009;13(3):148-51.

17. Sarmah N, Sarmah A, Das DK. A Study on the Microbiological Profile of Respiratory Tract Infection (RTI) in Patients Attending Gauhati Medical College \& Hospital. Ann Int Med Den Res. 2016;2(5):11-5.

18. Mishra SK, Kattel HP, Acharya J, Shah NP, Shah AS, Sherch JB, Rijal BP, Pokhrel BM. Recent trend of bacterial aetiology of lower respiratory tract infections in a tertiary care center of Nepal. Int J Infect Microbiol. 2012;1(1):3-8.

19. Okesola AO, Ige OM. Trends in Bacterial Pathogens of Lower Respiratory Tract Infections. Indian J Chest Dis Allied Sci. 2008;50:269-72.

Cite this article as: Hussain A, Sultana Q, Ansari MAR. A prospective study of prevalence of antimicrobial susceptibility of bacterial isolates in lower respiratory tract infections. Int J Basic Clin Pharmacol 2021;10:915-9. 